\title{
Strain Test for Evaluation of Rubber Compounds ${ }^{1}$
}

\author{
By Frank L. Roth and Robert D. Stiehler
}

\begin{abstract}
Measurements of elongation of rubber vulcanizates at a fixed stress have been made with a precision much greater than can be obtained in the usual measurements of stress at a specified elongation. Such measurements form the basis of a strain test developed to characterize rubber vulcanizates in control and research testing. Statistical analyses show that the errors introduced in the actual strain measurements are negligible compared to those introduced by variations during compounding and curing, whereas the errors introduced by the usual measurements of stress at a specified elongation are of the same order of magnitude. The high precision of strain testing has been used to detect variations within a single sheet of vulcanized rubber and variations among sheets cured from the same compounded batch. It has also been possible to determine with a single sheet its change in stiffness or modulus with age. The uniform treatment of specimens in the strain test makes them particularly useful for precise measurements of set. Further, it has been found that the decrease in elongation with time of cure apparently follows the laws of a second-order chemical reaction, and consequently it is possible to represent the data by an equation involving three vulcanization parameters.
\end{abstract}

\section{Introduction}

The inherent variability of measurements for determining the stress-strain properties of vulcanized rubber is notorious. It has been customary to ascribe the cause of the variability entirely to the rubber. This allegation may be largely true in the case of stress and elongation at failure, but measurements by means of the strain test definitely show that the measurements are responsible for a large portion of the observed variations of points on the stress-strain curve below failure.

Since the advent of the Government Synthetic Rubber Program in 1943, there has been an intensified effort to improve the precision of stressstrain testing. Measurements of the stress-temperature relationships for pure gum vulcanizates of GR-S and natural rubber by Roth and Wood $[1,2]^{2}$ suggested that the precision and accuracy of stress-strain measurements might be greatly improved by measuring the elongations of rubber specimens suspending predetermined loads. Strain

1 Presented before the Division of Rubber Chemistry at the 113th Meeting of the American Chemical Society, Chicago, Ill.

${ }^{2}$ Figures in brackets indicate the literature references at the end of this paper. tests made in late 1944 on vulcanizates of $\mathrm{X}-125$ GR-S and in 1945 on vulcanizates of natural rubber at the Instituto Agronomico do Norte in Belem, Brazil [3] confirmed this suggestion. In the development of this test, strain measurements for the evaluation of vulcanized rubber have been found to yield information that has not been revealed by the usual stress-strain measurements.

\section{Procedure}

In the strain test, a predetermined load is applied to a specimen and the elongation is measured after the load has been applied for a specified time. The load is selected to produce a specified force per unit of cross-sectional area of the unstretched specimen.

The early tests were performed with extremely simple equipment that required manual application of the load to a standard dumbbell-shaped specimen having a reduced section 2 in. long. Most of the data reported here, however, were obtained by means of a tester developed by Holt, Knox, and Roth [4]. This tester is designed to minimize the number of manual operations and thereby to reduce the number of subjective errors. 
These authors also describe the preparation of the test specimens and the measurement of their thickness, in addition to the measurement of strain at the specified stress. Strip specimens approximately $1 / 4 \mathrm{in}$. wide and $6 \mathrm{in}$. long are used, since specimens with enlarged ends are not required for this test. These specimens can be cut from the standard 6 by 6 by 0.075 -in. test sheet and permit the distance between bench marks to be increased to improve precision. The bench marks are spaced $10 \mathrm{~cm}$. apart, so that elongations can be read directly by means of a millimeter scale.

In early experiments, a stress of 1,000 psi (pounds per square inch) was used for vulcanized specimens of GR-S and GR-I prepared according to the Specifications for Government Synthetic Rubbers [5]. In the course of development of the method, the stress has been reduced in several steps to 400 psi which is employed at present for vulcanized tread-type compounds. The stress of 400 psi was selected because it is in the region where the ratio of elongation to stress attains a maximum value. A stress of 100 psi has been selected for gum vulcanizates of natural and other rubbers in order to avoid effects of crystallization. The stress of 100 psi can also be used for studying gum vulcanizates of GR-S.

For control testing and many research purposes, stresses of 100 to 400 psi are sufficient. Accordingly, the tester developed by Holt, Knox, and Roth [4], is provided with weights for applying a stress of 100,200 , or 400 psi. Stresses lower than 100 psi can be used, provided the elongation is above 50 percent. Minor modifications in the apparatus or procedure are necessary in order to measure precisely lower elongations. Stresses higher than 400 psi are obtained by suitable adjustment of the weights and are limited only by the strength of the specimen or the limiting extension of the specimen by the tester.

When the load is applied, the specimen elongates rapidly at first and then more slowly as time elapses. The precision of measurement increases as the rate of creep decreases, thus observations can be made with greater precision as the time after application of the load increases. It is necessary, however, in a control test to keep the time for making a test at a minimum compatible with the requisite precision.

Measurements have been made at various intervals between $10 \mathrm{sec}$ and $10 \mathrm{~min}$ after application of the load. These measurements indicated that the elongation of the specimen increases approximately linearly with the logarithm of time. For example, in figure 1, the increase in elongation after the 10-sec reading is plotted against the logarithm of time. The test specimens were prepared from GR-S according to the Specifications for Government Synthetic Rubbers [5]. Vulcanizates cured 25 and $90 \mathrm{~min}$ at $292^{\circ} \mathrm{F}$ were employed. Specimens cured $25 \mathrm{~min}$ were tested with loads of both 100 and 400 psi to determine the effect of load. The specimens cured $90 \mathrm{~min}$ were tested only with a load of 400 psi.

As can be seen in the figure 1, the rate of creep is approximately the same for the two loads, whereas the rate of creep for specimens cured 90 min is approximately one-third of that for those cured $25 \mathrm{~min}$. None of the natural or other synthetic rubber vulcanizates investigated, including some without fillers, had a greater rate of creep than the GR-S carbon-black compound

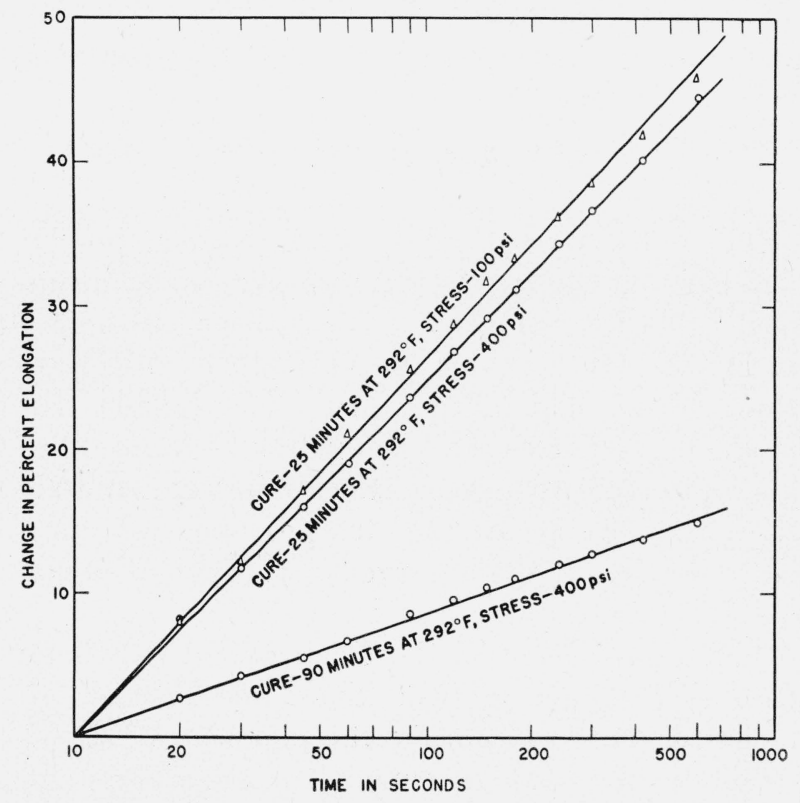

Figure 1. Creep of GR-S specimens under tensile stress.

The creep is shown as the difierence bstween the elongation at any specified time and that at 10 seconds after application of the stress. The time scale is locarithmic.

cured $25 \mathrm{~min}$ at $292^{\circ} \mathrm{F}$. In those cases where crystallization occurred, the rate of creep was a maximum at intermediate loads. This phenomenon is in accordance with the observations for unvulcanized natural rubber by Treloar [6] and for 
vulcanized natural rubber by Field [7] and by Wildschut [8].

From these studies, a time interval of $60 \mathrm{sec}$ was selected for making subsequent measurements, since observations made between 56 and 64 sec are less in error due to creep than to errors in determining cross-sectional area of the specimen. With the automatic timing of the tester designed by Holt, Knox, and Roth [4], it is possible to retain the same precision with shorter time intervals by reducing the period permitted for observation by a proportionate amount; that is, measurements made between 28 and $32 \mathrm{sec}$ are as precise as those made between 56 and 64 sec. The absolute value of the elongation, however, will be lower at $30 \mathrm{sec}$ than at $60 \mathrm{sec}$, as indicated in figure 1.

\section{Precision of Test}

The high precision of the strain test is achieved largely by measurement of the elongation under nearly static conditions, instead of taking observations as the specimen is being extended. This precision can be seen in table 1 , which gives the standard deviations among specimens from the same sheet of vulcanized rubber. The values represent data obtained during the evaluation of reference lots of Government Synthetic Rubbers. With the exception of the values for X-125 GR-S, which were obtained with 2 -in. dumbbell specimens and manually applied loads, the standard deviations are essentially identical for all rubbers tested during the past 3 years and are comparatively small. Because these values are in units of elongation, they cannot be compared directly with those for tensile stress. A comparison can be made, however, by converting one into the units of the other. In table 2 the standard deviations for strain are converted into equivalent stress values and compared with those for tensile stress as follows:

1. Six sheets from the same compounded batch of X-243 GR-S were cured for each of the times indicated; 3 sheets of each cure were used for measurements of tensile stress and three for those of strain.

2. The tensile stress at 300-percent elongation was measured on 6 specimens from each of the 3 sheets; the elongation was measured on 18 specimens from each sheet, 6 at a stress approximatelv equivalent to the average tensile stress at 300 -
TABle 1. Precision of strain measurements

\begin{tabular}{|c|c|c|c|c|c|c|c|}
\hline \multirow{2}{*}{\multicolumn{2}{|c|}{$\begin{array}{l}\text { Type of } \\
\text { rubber }\end{array}$}} & \multirow{2}{*}{$\begin{array}{l}\text { Date of } \\
\text { tests }\end{array}$} & \multirow{2}{*}{$\begin{array}{l}\text { Num- } \\
\text { ber of } \\
\text { sheets } \\
\text { tested }\end{array}$} & \multirow{2}{*}{ Stress } & \multicolumn{3}{|c|}{$\begin{array}{l}\text { Standard deviations of } \\
\text { strains for specimens } \\
\text { within a sheet }\end{array}$} \\
\hline & & & & & $25 \min b$ & $50 \min ^{b}$ & $90 \min ^{b}$ \\
\hline \multirow{17}{*}{ GR-S } & & & & $p 3 i$ & Percent & Percent & Percent \\
\hline & $\mathrm{X}-125^{a}$ & Dec. 1944 & 2 & 1,000 & 7.5 & 5. 9 & 4. 3 \\
\hline & $\mathrm{X}-179$ & Feb. 1945 & 22 & 1,000 & 2. 8 & 2.5 & 1.4 \\
\hline & $\mathrm{X}-224 \ldots$ & July 1945 & 9 & 1,000 & 4. 9 & 2.4 & 1. 7 \\
\hline & $\mathrm{X}-224 \ldots$ & July 1945 & 9 & 1,000 & 3.8 & 2. 2 & 1.9 \\
\hline & $\mathrm{X}-224$ & July 1945 & 9 & 1,000 & 2. 6 & 2. 0 & 1.9 \\
\hline & $\mathrm{X}-243 \ldots$ & Dec. 1945 & 20 & 1,000 & 3.3 & 1. 7 & 1.8 \\
\hline & $\mathrm{X}-224 \ldots$ & Apr. 1946 & 12 & 750 & 1.5 & 3.1 & 1.8 \\
\hline & $\mathrm{X}-289 \ldots$ & A pr. 1946 & 12 & 750 & 2.0 & 3. 2 & 1. 2 \\
\hline & $\mathrm{X}-289 \ldots$ & Jan. 1947 & 11 & 600 & 3.0 & 1. 1 & 0.9 \\
\hline & $\mathrm{X}-346 \ldots$ & Jan. 1947 & 21 & 600 & 3.0 & 1.5 & .8 \\
\hline & $\mathrm{X}-346 \ldots$ & July 1947 & 20 & 600 & 2. 6 & 2. 2 & 1. 4 \\
\hline & $\mathrm{X}-387 \ldots$ & July 1947 & 40 & 600 & 3.1 & 2. 0 & 1. 4 \\
\hline & $X-387 \ldots$ & Dec. 1947 & 16 & 600 & 3. 2 & 1.5 & 1.8 \\
\hline & $X-418 \ldots$ & Dec. 1947 & 36 & 600 & 3.5 & 2.1 & 1. 3 \\
\hline & $X-412 \ldots$ & Dec. 1947 & 30 & 600 & 3.8 & 1.5 & 2. 8 \\
\hline & $X-418 \ldots$ & Feb. 1948 & 54 & 400 & 2.5 & 1. 2 & ${ }^{c} 0.7$ \\
\hline \multirow{5}{*}{ GR-I } & & & & & $20 \min ^{d}$ & $40 \mathrm{~min}^{d}$ & $80 \min ^{d}$ \\
\hline & $\mathrm{Y}-100 \ldots$ & Apr. 1945 & 20 & 1,000 & 3.3 & 2. 9 & 2. 3 \\
\hline & $Y-102 \ldots$ & Jan. 1947 & 8 & 600 & 1.7 & 1.5 & 1.3 \\
\hline & $\mathrm{Y}-103 \ldots$ & Jan. 1947 & 16 & 600 & 1.6 & 1.1 & 1. 2 \\
\hline & & & & & $10 \min ^{b}$ & $10 \mathrm{~min}^{d}$ & $20 \mathrm{~min}^{d}$ \\
\hline \multicolumn{2}{|c|}{ GR-M (10 lots) - } & July 1946 & 20 & 609 & 3.1 & 2.5 & 2. 2 \\
\hline
\end{tabular}

a Used 2-in. dumbbell-shaped specimens and applied load manually.

b Time of cure at $292^{\circ} \mathrm{F}$.

c Cured $100 \mathrm{~min}$ at $292^{\circ} \mathrm{F}$.

$d$ Time of eure at $307^{\circ} \mathrm{F}$.

percent elongation, 6 at a stress 50 psi lower, and 6 at a stress 50 psi higher. The mean values for each of these properties are shown in the first 4 lines of table 2 .

3. The standard deviations among specimens were calculated for tensile stress and for strain measurements and are given in lines 5 and 6 of table 2. The change in elongation produced by a change in stress of 1 psi were calculated from the strain measurements in lines 2 to 4 and are shown in line 7 . The values of the standard deviations in line 6 were divided by the corresponding values in line 7 to obtain the equivalent standard deviations in units of stress shown in line 8.

4. The ratios of the values in line 5 to those in line 8 , given in the last line, indicate that the standard deviations for tensile stress measurements at 300-percent elongation are approximately $2 \frac{1}{2}$ times as large as the equivalent values for strain measurements.

Another comparison of the precision of measurements made by these two methods of test is 
TABLE 2. Comparison of precision of strain test with precision of usual tensile stress test

\begin{tabular}{|c|c|c|c|c|c|c|c|c|}
\hline \multirow{3}{*}{ Line } & \multirow{3}{*}{ Test } & \multirow{3}{*}{ Statistic } & \multicolumn{6}{|c|}{ Compounds of X-243 GR-S vulcanized } \\
\hline & & & \multicolumn{2}{|c|}{$25 \mathrm{~min}$ at $292^{\circ} \mathrm{F}$} & \multicolumn{2}{|c|}{$50 \mathrm{~min}$ at $292^{\circ} \mathrm{F}$} & \multicolumn{2}{|c|}{$90 \mathrm{~min}$ at $292^{\circ} \mathrm{F}$} \\
\hline & & & Stress & Strain & Stress & Strain & Stress & Strain \\
\hline 1 & Stress & Mean & $\begin{array}{r}p s i \\
407\end{array}$ & $\begin{array}{l}\text { Percent } \\
300\end{array}$ & $\begin{array}{r}p s i \\
1,089\end{array}$ & $\begin{array}{l}\text { Percent } \\
300\end{array}$ & $\begin{array}{r}p s i \\
1,543\end{array}$ & $\begin{array}{l}\text { Percent } \\
300\end{array}$ \\
\hline 2 & Strain .. & ..... do & 350 & 298.9 & 1,050 & 324.7 & 1,500 & 330.1 \\
\hline 3 & ..... do ... & ...... do _. & 400 & 328.9 & 1,100 & 335.2 & 1,550 & 338.2 \\
\hline 4 & -..... do & ...... do ... & 450 & 355.3 & 1,150 & 344.8 & 1,600 & 348.8 \\
\hline 5 & Stress _- & Std. dev. $a_{\ldots}$ & 18.8 & & 30.2 & & 45.2 & \\
\hline 6 & Strain.. & ..... do a .... & (n......... & 4. 36 & ..... & 3.26 & -... & 2. 74 \\
\hline 7 & ..... do & $\triangle E / \triangle S^{\mathrm{b}}$ & & 0.564 & & 0.201 & & 0.187 \\
\hline 8 & $\ldots$ do $\ldots$ & Std. $\operatorname{dev} . \mathrm{e}_{-}$ & 7.72 & ( & 16. 2 & ........... & 14.7 & - \\
\hline 9 & 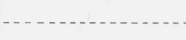 & Ratio d...... & 2. 44 & - & 1.86 & - & 3.07 & (n)......... \\
\hline
\end{tabular}

a Standard deviation of specimens within a sheet.

b The change in elongation for a change in stress of 1 psi (line 4 minus line 2)/100.

c Standard deviation of strain measurements expressed in equivalent stress units, which is calculated by dividing the strain standard deviation by $\Delta E / \Delta S$, line $6 /$ line 7.

d Ratio of standard deviation for tensile stress to that for strain both expressed in psi, line $5 /$ line 8 .

possible by subjecting the data obtained on reference lots of synthetic rubbers to an analysis of

TABLE 3. Variances of stress and strain measurements a

\begin{tabular}{|c|c|c|c|c|c|}
\hline \multirow{3}{*}{ Type of GR-S } & \multirow{3}{*}{$\begin{array}{l}\text { Cured at } \\
292^{\circ} \mathrm{F} \\
\text { for - }\end{array}$} & \multicolumn{4}{|c|}{ Variances } \\
\hline & & A & B & $\mathrm{C}$ & $\mathrm{D}$ \\
\hline & & $\begin{array}{l}\text { Batch } \\
\text { means b }\end{array}$ & $\begin{array}{l}\text { Speci- } \\
\text { mens c }\end{array}$ & Col. B/5 & $\begin{array}{l}\text { Col. } \\
\text { C/A }\end{array}$ \\
\hline \multicolumn{6}{|c|}{ STRESS AT 300 PERCENT ELONGATION } \\
\hline $\mathrm{X}-346$ & $\begin{array}{c}\min \\
25 \\
50 \\
90\end{array}$ & $\begin{array}{r}\text { psi }{ }^{2} \\
509 \\
824 \\
708\end{array}$ & $\begin{array}{l}p s i^{2} \\
1,320 \\
1,297 \\
1,801\end{array}$ & $\begin{array}{c}p s i^{2} \\
264 \\
259 \\
360\end{array}$ & $\begin{array}{c}\text { Percent } \\
52 \\
31 \\
51\end{array}$ \\
\hline $\mathrm{X}-289$ & $\left\{\begin{array}{l}25 \\
50 \\
90\end{array}\right.$ & $\begin{array}{r}133 \\
658 \\
1,847\end{array}$ & $\begin{array}{r}276 \\
931 \\
1,120\end{array}$ & $\begin{array}{r}55 \\
186 \\
224\end{array}$ & $\begin{array}{l}41 \\
28 \\
12\end{array}$ \\
\hline \multicolumn{6}{|c|}{ STRAIN AT 600 PSI } \\
\hline $\mathrm{X}-346 \ldots$ & $\left\{\begin{array}{l}25 \\
50 \\
90\end{array}\right.$ & $\begin{array}{c}\text { Percent }^{2} \\
78.9 \\
24.6 \\
1.8\end{array}$ & $\begin{array}{c}\text { Percent }{ }^{2} \\
9.00 \\
2.16 \\
0.65\end{array}$ & $\begin{array}{c}\text { Percent } 2 \\
1.80 \\
0.43 \\
.13\end{array}$ & $\begin{array}{c}\text { Percent } \\
2.3 \\
1.8 \\
7.2\end{array}$ \\
\hline $\mathrm{X}-289$ & $\left\{\begin{array}{l}25 \\
50 \\
90\end{array}\right.$ & $\begin{array}{r}56.0 \\
5.3 \\
8.9\end{array}$ & $\begin{array}{l}8.86 \\
1.12 \\
0.73\end{array}$ & $\begin{array}{r}1.77 \\
0.22 \\
.15\end{array}$ & $\begin{array}{l}3.2 \\
4.2 \\
1.7\end{array}$ \\
\hline
\end{tabular}

a Analysis of variances is treated in such books as Statistical methods in research and production, by O. L. Davies, published by Oliver and Boyd, London (1947) for Imperial Chemical Industries, Ltd., or Statistical methods, by George W. Snedecor, Iowa State College Press (1946).

b Variances apply to 27 batches of X-346 GR-S and 11 batches of X-289 GR-S.

- Variances apply to 5 specimens from a sheet from each batch, i. e., a total of 105 specimens of $\mathrm{X}-346$ and 55 specimens of $\mathrm{X}-289 \mathrm{GR}-\mathrm{S}$. variance. Such an analysis for X-289 and X-346 GR-S is given in table 3. Column A lists for each property the variances (squares of standard deviations) among batch means, and column B lists the variances among specimens from the same batch. The values in column A may be resolved into two components, one due to variations from batch to batch and the other to variations among specimens from the same batch. Since five specimens from each batch were tested, the contributions from variations among specimens to the variances in column $\mathrm{A}$ are one-fifth of the variances in column B and are listed in column C. Column D expresses this contribution as a percentage of the observed variance among the batch means. In the case of elongation at 600 psi, testing variations account for approximately 3.4 percent of the observed batch-to-batch variations, which is about one-tenth the corresponding percentage for stress at 300-percent elongation. Similar results have been obtained in the evaluation of $\mathrm{Y}-102$ and $\mathrm{Y}-103 \mathrm{GR}-\mathrm{I}$. Other laboratories [9,10], have noted comparable improvements in precision of testing by means of the strain test.

\section{Applications of Strain Test}

The high precision of the strain test has made it possible to obtain a reliable evaluation of vulcanized rubber samples by means of relatively few measurements. For example, it has been possible to determine with little effort the variations intro- 
duced during compounding and curing, the heterogeneity of a single sheet of rubber, and the change in stress-strain properties during storage of vulcanized rubber.

In table 3 the large variance among batch means compared to the variance among specimens for the strain data indicates that there was considerable variability in the compounding and curing operations. Similar data are shown in table 4 , where values for individual specimens from five batches

TABLE 4. Typical data for strain and set of individual specimens

\begin{tabular}{|c|c|c|c|c|c|c|}
\hline \multirow{2}{*}{ Date, 1946} & \multicolumn{3}{|c|}{ Strain at $600 \mathrm{psi}$} & \multicolumn{3}{|c|}{ Set b } \\
\hline & $25 \min ^{a}$ & $\begin{array}{c}50 \\
\min { }^{a}\end{array}$ & $\begin{array}{c}90 \\
\min { }^{a}\end{array}$ & $\stackrel{25}{\min }$ a $^{25}$ & $\begin{array}{c}50 \\
\text { min a }\end{array}$ & $\begin{array}{c}90 \\
\text { min a }\end{array}$ \\
\hline \multirow[t]{2}{*}{ Oet. $22 \ldots$} & $\begin{array}{r}\text { Percent } \\
450 \\
450 \\
452 \\
456 \\
457\end{array}$ & $\begin{array}{l}\text { Per- } \\
\text { cent } \\
245 \\
245 \\
242 \\
245 \\
245\end{array}$ & $\begin{array}{c}\text { Per- } \\
\text { cent } \\
190 \\
190 \\
192 \\
191 \\
191\end{array}$ & $\begin{array}{l}\text { Per- } \\
\text { cent } \\
10.5 \\
10.5 \\
10.5 \\
10.6 \\
10.6\end{array}$ & $\begin{array}{l}\text { Per- } \\
\text { cent } \\
\text { 4. } 5 \\
4.5 \\
4.6 \\
4.3 \\
4.5\end{array}$ & $\begin{array}{c}\text { Per- } \\
\text { cent } \\
3.0 \\
3.0 \\
3.2 \\
3.0 \\
3.2\end{array}$ \\
\hline & Avg_.453 & 244 & 191 & 10.5 & 4. 5 & 3.1 \\
\hline \multirow[t]{2}{*}{ Oet. $23 \ldots$} & $\begin{array}{l}492 \\
485 \\
484 \\
488 \\
485\end{array}$ & $\begin{array}{l}256 \\
256 \\
256 \\
255 \\
257\end{array}$ & $\begin{array}{l}190 \\
190 \\
192 \\
190 \\
190\end{array}$ & $\begin{array}{l}10.5 \\
10.8 \\
10.7 \\
10.7 \\
10.7\end{array}$ & $\begin{array}{l}4.8 \\
4.8 \\
4.8 \\
5.0 \\
5.0\end{array}$ & $\begin{array}{l}3.2 \\
3.4 \\
3.3 \\
3.3 \\
3.3\end{array}$ \\
\hline & Avg_. 487 & 256 & 190 & 10.7 & 4. 9 & 3.3 \\
\hline \multirow[t]{2}{*}{ Oct. 24} & $\begin{array}{l}486 \\
484 \\
481 \\
485 \\
485\end{array}$ & $\begin{array}{l}248 \\
250 \\
250 \\
250 \\
249\end{array}$ & $\begin{array}{l}193 \\
194 \\
194 \\
192 \\
193\end{array}$ & $\begin{array}{l}13.4 \\
13.4 \\
13.4 \\
13.6 \\
13.6\end{array}$ & $\begin{array}{l}5.0 \\
5.0 \\
4.9 \\
4.9 \\
5.0\end{array}$ & $\begin{array}{l}3.0 \\
3.0 \\
3.5 \\
3.5 \\
3.5\end{array}$ \\
\hline & Avg_. 484 & 249 & 193 & 13.5 & 5. 0 & 3.3 \\
\hline \multirow[t]{2}{*}{ Oct. $29 \ldots$} & $\begin{array}{l}446 \\
446 \\
445 \\
448 \\
446\end{array}$ & $\begin{array}{l}244 \\
241 \\
243 \\
242 \\
240\end{array}$ & $\begin{array}{l}190 \\
190 \\
190 \\
190 \\
190\end{array}$ & $\begin{array}{l}12.0 \\
12.3 \\
12.3 \\
12.4 \\
12.3\end{array}$ & $\begin{array}{l}4.4 \\
4.4 \\
4.2 \\
4.3 \\
4.3\end{array}$ & $\begin{array}{l}3.8 \\
3.8 \\
3.6 \\
3.7 \\
3.6\end{array}$ \\
\hline & Avg_.446 & 242 & 190 & 12.3 & 4. 3 & 3.7 \\
\hline \multirow[t]{2}{*}{ Oct. 30} & $\begin{array}{l}486 \\
486 \\
486 \\
485 \\
487\end{array}$ & $\begin{array}{l}252 \\
252 \\
250 \\
249 \\
247\end{array}$ & $\begin{array}{l}193 \\
191 \\
190 \\
189 \\
188\end{array}$ & $\begin{array}{l}13.5 \\
13.5 \\
13.2 \\
13.5 \\
13.4\end{array}$ & $\begin{array}{l}5.0 \\
5.0 \\
5.0 \\
5.0 \\
4.9\end{array}$ & $\begin{array}{l}3.4 \\
3.5 \\
3.5 \\
3.4 \\
3.5\end{array}$ \\
\hline & Avg_.486 & 250 & 190 & 13.4 & 5. 0 & 3.5 \\
\hline
\end{tabular}

a Time of cure at $292^{\circ} \mathrm{F} . \mathrm{X}-289 \mathrm{GR}-\mathrm{S}$ vulcanizates prepared according to the Specifications for Government Synthetic Rubbers, effective Jan. 1, 1946.

b Set measurements made $1 \mathrm{hr}$ after strain measurements on same specimens. prepared on different days are given. The agreement among the specimens from a single sheet from each batch is excellent, but the batch averages vary considerably. In order to determine whether this variation is related to the compounding or curing procedure, 6 sheets from the same batch were vulcanized simultaneously. The average value for each of the 6 sheets is given in table 5 . The variation among sheets cured from the same batch is considerably more than expected from specimen variations and is an appreciable fraction of the variation among batches noted in table 4 . From an analysis of variance made on data, not reported here, for approximately 100 pairs of sheets of $\mathrm{X}-412$ and $\mathrm{X}-418$ GR-S vulcanizates, it was inferred that the true variance among batches is approximately two times the true variance among sheets within a batch.

TABLE 5. Strain and set data for sheets within a batch of $X-289$ GR-S vulcanizates

\begin{tabular}{|c|c|c|c|c|c|c|}
\hline \multirow{2}{*}{ Sheet } & \multicolumn{3}{|c|}{ Strain at $600 \mathrm{psi}$} & \multicolumn{3}{|c|}{ Set b } \\
\hline & $25 \min ^{\mathrm{a}}$ & $50 \min ^{a}$ & $90 \min ^{\mathrm{a}}$ & $25 \min { }^{a}$ & $50 \mathrm{~min} \mathrm{a}^{\circ}$ & $90 \min ^{\mathrm{a}}$ \\
\hline 1 & $\begin{array}{c}\text { Percent } \\
471\end{array}$ & $\begin{array}{c}\text { Percent } \\
254.6\end{array}$ & $\begin{array}{c}\text { Percent } \\
194.3\end{array}$ & $\begin{array}{c}\text { Percent } \\
12.15\end{array}$ & $\begin{array}{c}\text { Percent } \\
4.50\end{array}$ & $\begin{array}{c}\text { Percent } \\
3.23\end{array}$ \\
\hline $2 \ldots$ & 484 & 255.7 & 193. 7 & e 14.85 & 4. 74 & 3.16 \\
\hline 3. & 468 & 251. 2 & 192.9 & с 12.66 & 4.54 & 3.15 \\
\hline 4. & 498 & 258.0 & 191.5 & c 14.07 & 4. 91 & 3. 36 \\
\hline $5 \ldots$ & 465 & 253.0 & 192.9 & c 12.70 & 4. 68 & 3.36 \\
\hline $6 \ldots$ & 468 & 253.6 & 191.9 & 12.48 & - & • 3.23 \\
\hline Avr... & $4 i 6$ & 254.5 & 192.9 & 13.15 & 4. 67 & 3. 25 \\
\hline
\end{tabular}

a Time of cure at $292^{\circ} \mathbf{F}$.

b Set measurements were made $1 \mathrm{hr}$ after strain measurements on same specimens.

- Mean for 6 specimens, other values are means for 20 specimens.

In addition to its use for detecting compounding and curing variables, the strain test is sufficiently sensitive to detect variations within a single sheet of vulcanized rubber. The narrow specimen used in this test makes it possible to cut 20 specimens from a sheet 6 in. square. The variations among 20 such specimens are seen in figure 2. This figure shows the individual strain values for the sheets vulcanized 25 and $90 \mathrm{~min}$, respectively, and summarized in table 5. The elongation of each specimen is plotted in the order of its position in the sheet. The trends in values noted across most sheets are believed to be due to grain effects caused by flow during the early part of vulcanization. This conclusion 
is supported by the studies of Gurney and Gough [11].

Since 20 specimens can be cut from a single sheet, it is possible to study the change in stressstrain properties of vulcanized rubber during storage. Figure 3 shows the average change in five sheets of each of three GR-S vulcanizates during the first 6 days of storage at $82^{\circ} \mathrm{F}$. These data show the marked stiffening of undercured rubber during the first $24 \mathrm{hr}$ after vulcanization

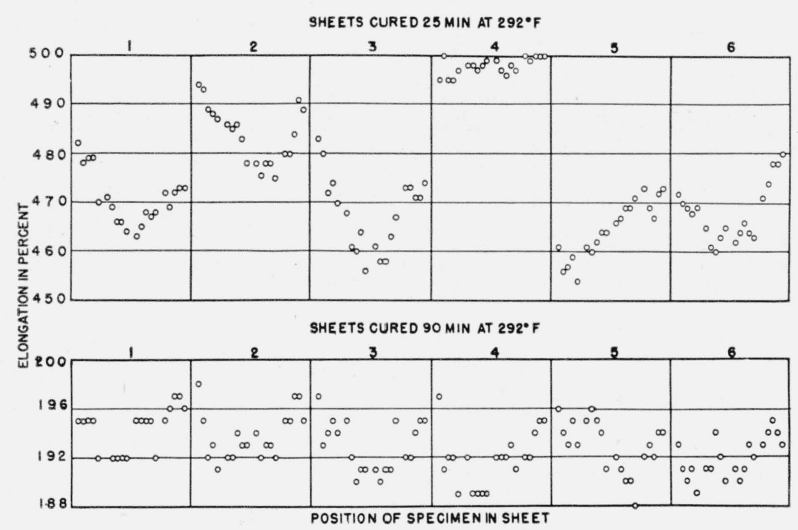

FIGURE 2. Heterogeneity within and among sheets from same compounded batch.

The mean value for each sheet and the conditions of test are given in table 5

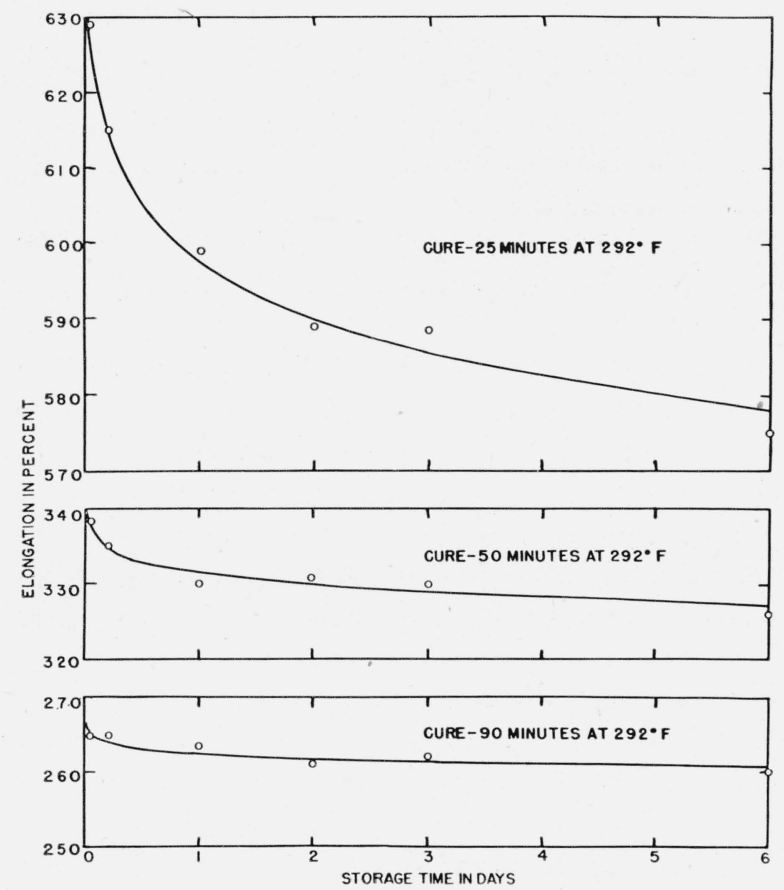

Figure 3. Effect of storage at $82^{\circ} \mathrm{F}$ on elongation at $600 \mathrm{lb} / \mathrm{in}^{2}$ for vulcanizates of $X-243 \mathrm{GR}-\mathrm{S}$. and support the minimum aging period of $24 \mathrm{hr}$ between vulcanization and testing required by ASTM Method D15-41 and of $16 \mathrm{hr}$ by the Specifications for Government Synthetic Rubbers. It should be emphasized that the strain test made it possible to obtain these results from only one batch for each cure.

\section{Method for Measuring Set}

Specimens subjected to the strain test can be conveniently used for precise measurement of extension set for a specified stress, since the specimens are subjected to a uniform stress for a uniform period of time. Such measurements of set after the specimens have been allowed to recover for $1 \mathrm{hr}$ are presented in table 4 . As seen in this table, the dispersion of values for specimens from the same sheet is remarkably small, so that it is easy to detect variations among sheets or batches. The results of set measurements shown in table 5 indicate that there is an appreciable variation in set among sheets from the same batch, although not as large as that among batches shown in table 4 .

\section{Determination of Vulcanization Parameters}

In the usual measurements of tensile stress ("modulus") of rubbers rulcanized for different periods of time, considerable ambiguity arises in differentiating between cure characteristics and the inherent stiffness of the rubber compound. An examination of strain data plotted as a function of time of cure, as in figure 4 , indicates that the curve is a rectangular hyperbola of the form $(t-a)(E-b)=c$, where $E$ is the elongation at time of cure, $t$. On differentiation, this equation becomes: $-d E / d t=(E-b)^{2} / C$. This equation suggests that elongation at a fixed stress decreases with time of cure according to the laws of a secondorder reaction, in which the reaction rate constant $(k)$ is $1 / C$. The parameter $b$ is independent of the time of cure and corresponds to the elongation $\left(E_{\infty}\right)$ for infinite cure time. The parameter $a$ is the constant of integration and corresponds to the time $\left(t_{0}\right)$ at which the elongation begins to decrease. This time may be considered as the point of incipient cure or scorch time. Thus, strain data may be useful for determining three parameters of vulcanization; (1) scorch time, $t_{0}$, (2) 
reaction rate constant, $k$, and (3) a structure factor, $E_{\infty}$, which may be associated with the inherent stiffness of the rubber compound. This stiffness may be due to the structure of the polymer or the nature and concentration of the compounding ingredients. As seen in figure $4, E_{\infty}$, is a function of the applied stress; whereas $t_{0}$ is independent of it. The reaction rate constant, $k$, is also a function of the applied stress that must be considered in comparing compounds with different stress-strain characteristics.

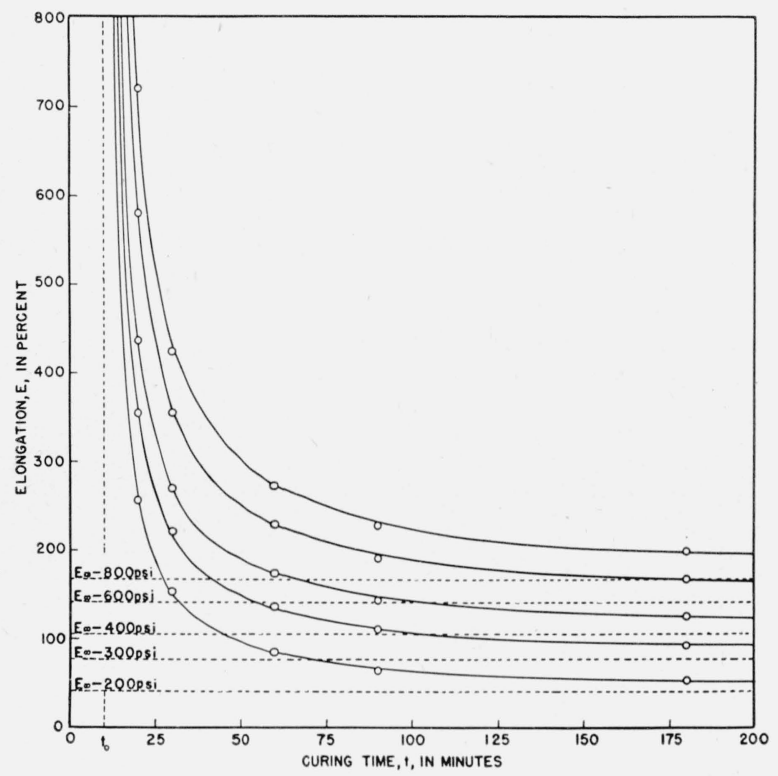

Figure 4. Elongations for various stresses versus time of vulcanization of $X-387 \mathrm{GR}-\mathrm{S}$ at $292^{\circ} \mathrm{F}$.

The solid lines are hyperbolas calculated from the equation, $\left(t-t_{0}\right)\left(E-E_{\infty}\right) k$ $=1$, with the following values for the parameters:

\begin{tabular}{|c|c|c|c|}
\hline Stress & $t_{0}$ & $E_{\infty}$ & $k$ \\
\hline lb/in..$^{2}$ & $\min$ & $\%$ & $(\min \times \%)^{-1}$ \\
\hline 200 & 11 & 41 & 0.000488 \\
\hline 300 & 11 & 78 & .000392 \\
\hline 400 & 11 & 107 & .000329 \\
\hline 600 & 11 & 142 & .000250 \\
\hline 800 & 11 & 168 & .000203 \\
\hline
\end{tabular}

This relationship has been found to apply to vulcanized GR-S, GR-M, and natural rubber compounds. In the case of rubbers that crystallize on stretching, however, $t_{0}$ decreases and may become negative as crystallization increases. Accordingly, if $t_{0}$ is to be regarded as a scorch time, the stress should be sufficiently low to avoid crystallization. Reversion is another phenomenon that affects the vulcanization parameters. When reversion occurs, $E$ reaches a minimum and then increases instead of approaching an asymptote as the cure time increases indefinitely. Further, the parameters are extremely sensitive to the observed variations between sheets noted in table 5. It is, therefore, essential to use the average value from several sheets in order to obtain reliable values for the parameters. Employing the average values obtained in the evaluation of $\mathrm{X}-289, \mathrm{X}-346$, and $\mathrm{X}-387 \mathrm{GR}-\mathrm{S}$, the constants given in table 6 were calculated for the vulcanization parameters, $t_{0}, k$, and $E_{\infty}$.

TABLE 6. Vulcanization parameters derived from strain data

\begin{tabular}{|c|c|c|c|c|}
\hline Type of GR-S & Date tested & $\begin{array}{c}\text { Scorch } \\
\text { time, } t_{0}\end{array}$ & $\begin{array}{l}\text { Reaction rate } \\
\text { constant, } k\end{array}$ & $\begin{array}{l}\text { Structure fac- } \\
\text { tor, } E_{\infty} \text { at } \\
600 \text { psi }\end{array}$ \\
\hline $\begin{array}{l}\mathrm{X}-289 \\
\mathrm{X}-289 \\
\mathrm{X}-346 \\
\mathrm{X}-346 \\
\mathrm{X}-387\end{array}$ & $\begin{array}{l}\text { Oet. } 1946 \\
\text { Jan. } 1947 \\
\text { Jan. } 1947 \\
\text { July } 1947 \\
\text { July } 1947\end{array}$ & $\begin{array}{l}\min \\
13.0 \\
12.1 \\
10.9 \\
11.0 \\
11.0\end{array}$ & $\begin{array}{c}(\min \times \%)^{-1} \\
0.000249 \\
.000239 \\
.000265 \\
.000247 \\
.000234\end{array}$ & $\begin{array}{c}\text { Percent } \\
138 \\
138 \\
135 \\
130 \\
136\end{array}$ \\
\hline
\end{tabular}

\section{References}

[1] F. L. Roth and L. A. Wood, J. App. Phys. 15, 749 (1944).

[2] L. A. Wood and F. L. Roth, J. App. Phys. 15, 781 (1944).

[3] N. Bekkedahl, Private communication.

[4] W. L. Holt, E. C. Knox, and F. L. Roth, J. Research NBS 41, 95 (1948) RP1907.

[5] Specifications for Government Synthetic Rubbers (Reconstruction Finance Corp., Office of Rubber Reserve, Washington 25, D. C., Jan. 1, 1947).

[6] L. R. G. Treloar, Trans. Faraday Soc. 36, part 4, 538 (1940). Reprinted in Rubber Chem. Tech. 13, 795 (1940).

[7] J. E. Field, J. App. Phys. 12, 23 (1941). Reprinted in Rubber Chem. Tech. 14, 555 (1941).

[8] A. J. Wildschut, Physica 10, 571 (1943). Reprinted in Rubber Chem. Tech. 17, 854 (1944).

[9] A. R. Crandall, Private communication.

[10] H. M. Leeper, Private communication.

[11] W. A. Gurney and V. E. Gough, Trans. IRI 22, 132 (1946). Reprinted in Rubber Chem. Tech. 20, 863 (1947).

Washington, April 16, 1948. 